\title{
Spermatic Stasis
}

National Cancer Institute

\section{Source}

National Cancer Institute. Spermatic Stasis. NCI Thesaurus. Code C120907.

Stoppage of flow of sperm due to obstruction. 